\title{
OS IMPACTOS DA FALSA ACUSAÇÃO EM PEQUENAS COMUNIDADES: POSSÍVEIS ENCONTROS ENTRE A SOCIOLOGIA E A CRIMONOLOGIA NO FILME "A CAÇA"
}

\section{Artur Fabro}

Vinculado à Universidade Federal de Santa Catarina. Mestre do Programa de Sociologia Política.

E-mail: arturfabro@gmail.com

Fernando Vechi

Mestrando do Programa de Ciências Criminais da Pontifícia Universidade Católica do Rio Grande do Sul - PUCRS E-mail: fvechi@gmail.com

\section{RESUMO}

Este trabalho visa demonstrar algumas perspectivas da sociologia e da criminologia perante uma falsa acusação de estupro dentro de uma pequena comunidade, caso este contido no filme "A caça". Utilizando um embasamento teórico das duas disciplinas, o presente esforço procura destrinchar a demanda punitiva presente na comunidade artificial do filme perante o hipotético cometimento de um crime sexual. 0 desenrolar do enredo nos mostra uma população que não reconhece (e reproduz) seus direitos básicos, como presunção de inocência, ampla defesa e contraditório. Nossa análise será desenvolvida a partir de uma investigação da obra cinematográfica em questão, unindo à utilização de conceitos de ambas as disciplinas para justificar nossas interpretações dos acontecimentos.

PALAVRAS-CHAVE: Criminologia. Sociologia. Teorema de Thomas. Rotulacionismo. Estigmatização. 


\section{INTRODUÇÃO}

Este artigo tem por objetivo operar com uma análise criminológica e sociológica do filme "A Caça" (2012) ${ }^{8}$, dirigido pelo dinamarquês Thomas Vinterberg. Utilizaremos, para nosso estudo, principalmente da ideia de estigma social ${ }^{9}$ do sociólogo canadense Erving Goffman; do entendimento que Howard Becker tem do outsider; e do tratamento dado a uma categoria de sujeitos que Eugenio Zaffaroni, em o Inimigo no Direito Penal, denomina como inimigo ou hostis ${ }^{10}$, muito parecido com a proposta de Goffman. Portanto, já podemos atestar aqui uma interlocução conceitual entre os campos da Sociologia e Criminologia, onde uniremos ambas as interpretações para produzirmos uma perspectiva social mais ampla, acompanhando a complexidade das relações sociais que o filme apresenta.

A história se concentra na vida do personagem Lucas, interpretado por Mads Mikkelsen, que recebe uma falsa acusação de estupro de uma menina chamada Klara, de cinco anos, filha de seu melhor amigo. A garota, em determinado momento do filme, ouve palavras com conotação sexual de seu irmão mais velho e, após nutrir uma espécie de paixão por Lucas, acaba relatando para a diretora da creche que este havia lhe mostrado o órgão genital, em uma cena onde a confusão mental de Klara transparece sua insegurança perante o fato relatado.

Desta forma, utilizando também do pensamento de Howard Becker em Outsiders ${ }^{11}$, percebe-se que, após Klara “denunciar” Lucas, existe uma suposta quebra de regra social e a

\footnotetext{
${ }^{8}$ Em dinamarquês - Jagten.

9 "Enquanto o estranho está à nossa frente, podem surgir evidências de que ele tem um atributo que o torna diferente de outros que se encontram numa categoria em que pudesse ser - incluído, sendo, até, de uma espécie menos desejável - num caso extremo, uma pessoa completamente má, perigosa ou fraca. Assim, deixamos de considerá-lo criatura comum e total, reduzindo-o a uma pessoa estragada e diminuída. Tal característica é um estigma, especialmente quando o seu efeito de descrédito é muito grande - algumas vezes ele também é considerado um defeito, uma fraqueza, uma desvantagem - e constitui uma discrepância específica entre a identidade social virtual e a identidade social real" (GOFFMAN, 2013, p. 6).

${ }^{10} \mathrm{O}$ conceito de inimigo, referenciado por Zaffaroni como o Hostis em sua obra "O Inimigo no Direito Penal" tem origem no direito romano e foi usado na teoria política por Carl Schmitt. Muitos foram os inimigos ao longo das épocas, como coloca o autor, por onde o sistema punitivo e seletivo organizou categorias e sujeitos passíveis de eliminação.

${ }^{11}$ A obra de Becker se insere em um novo paradigma na criminologia designado pelo nome de Labelling approach. Este paradigma se encontra no enfoque da perspectiva ou teoria do "interacionismo simbólico, etiquetamento, rotulação ou ainda por paradigma da "reação social" (social reation approach), do "controle" ou da "definição. "[...] na verdade, Outsiders persiste ainda como a obra central do labelling, a primeira onde esta nova perspectiva aparece consolidada e sistematizada e onde se encontra definitivamente formulada a sua tese central" (ANDRADE, 1995, p. 27).
} 
imposição de um rótulo ${ }^{12}$ a este personagem. Lucas estava em uma situação não-convencional dentro da pequena cidade. Foi-lhe atribuído um estigma de caráter individual que atribui uma identidade virtual (de estuprador) e que atribui um status moral negativo, pois contrariava valores e práticas dentro daquela comunidade. Somado a isso, o personagem tinha acabado de enfrentar um divórcio tumultuoso e perdeu a guarda de seu filho. Inconcebível um sujeito com estas características ficar impune após cometer um crime de caráter sexual. Este tipo de desvio numa pequena população promove um alto valor moral e sentimental entre as pessoas e isto acaba por despontar em revolta e medo.

Assim sendo, as relações sociais anteriormente mantidas por Lucas serão fortemente abaladas dentro do seio da comunidade, tendo o mesmo a necessidade de se provar inocente para garantir sua "sobrevivência social", isto é, nas palavras de Émile Durkheim, de cessar a anomia $^{13}$. O contexto-social do filme é de extrema importância para o desenvolvimento da história, pois demonstra com detalhes algumas facetas que grupos sociais desenvolvem a partir de certos acontecimentos que transgredem sua pretensa ordem, tendendo, na maioria das vezes, a fazerem de tudo para conservarem um status quo já estabelecido.

\section{O MUNDO SOCIAL NO FILME “A CAÇA”}

A convivência em sociedade pressupõe um conjunto de comportamentos que se padronizem ao longo das gerações e constituam o que se pode denominar de "comportamento normal”, enquanto aqueles que fogem a estas regras de comportamento possuem uma espécie de anormalidade ou desvio. A "sociologia do desvio", que tem como maiores representantes Goffman e Becker, busca compreender o que distingue um comportamento desviante de outros tipos de comportamento considerados "normais". Becker não entende o desvio como uma característica personal do sujeito, como se existissem pessoas mais ou menos propensas a serem desviantes, mas sim leva em conta a formalização de um caráter desviante perante o

\footnotetext{
${ }^{12}$ A definição de rótulo pode ser entendida como uma atribuição designadora de um comportamento considerado negativamente desviante visto pelos outros, como, por exemplo, no caso do desvio criminal, aqueles que modulariam esse rótulo de desviante são as instituições penais (polícia, justiça, instituições penitenciárias, etc.). ${ }^{13} \mathrm{O}$ conceito de anomia social - do sociólogo francês Émile Durkheim - inaugura uma primeira teorização sobre esse "comportamento desviante" visto por Durkheim nas sociedades ocidentais modernas. O autor desenvolve sua ideia de anomia em duas importantes obras: O Suicídio (1897) e A divisão do trabalho social (1893). "E a este estado de anomia que devem ser atribuídos, como mostraremos, os conflitos incessantemente renovados e as desordens de todos os tipos dos quais o mundo econômico nos dá o triste espetáculo. Porque, como nada contém as forças litigantes e não lhes designa os limites que devem respeitar, elas tendem a se desenvolver sem limites, e acabam por se chocar umas contra as outras para se recalcarem e se reduzirem mutuamente. Sem duvida, as mais intensas conseguem muito bem aniquilar as mais fracas ou subordina-las" (DURKHEIM, 1983, p.4).
} 
entendimento dos outros do que seria um desvio, ou seja, o desvio somente se materializa graças a um consenso do que é ser desviante. Em uma hipotética comunidade onde a pedofilia não é crime e nem uma atitude moralmente condenada, Lucas não estaria passando por nenhum constrangimento, mesmo esse constrangimento sendo ou não uma mentira.

Já para Goffman, assim como para Foucault, as instituições seriam as grandes responsáveis pelos estatutos da normalidade. Cada indivíduo passaria, no decorrer de sua vida, por instituições como manicômios, exército, conventos, hospitais, escolas etc. que atestariam sua normalidade ou não perante seus procedimentos específicos. $\mathrm{O}$ "processo de deterioração" que essas entidades provocam com a identidade do sujeito vai ao sentido de substitui-la por aquela criada e cultivada por elas, tendo uma ideia forte de panoptismo, que Foucault, ao estudar as prisões em Vigiar e punir, oferece uma interessante definição do sentimento de vigilância constante:

\begin{abstract}
A multidão, massa compacta, local de múltiplas trocas, individualidades que se fundem, efeito coletivo, é abolida em proveito de uma coleção de individualidades separadas. Do ponto de vista do guardião, é substituída por uma multidão enumerável e controlável; do ponto de vista dos detentos, por uma solidão sequestrada e olhada (FOUCAULT, 2011, pp.190-191).
\end{abstract}

Quando surge um caso desviante no filme, um comportamento que ofende gravemente a moralidade das pessoas nesta pequena comunidade, as pessoas tendem ao máximo canalizar o mal no outro, e não em si, pelo fato de que neste ambiente estão presentes comportamentos altamente homogêneos e, desta forma, a comunidade será altamente refratária ao que se denomina outsider ${ }^{14}$, visando manter a estabilidade e a padronização dos comportamentos. É um mecanismo de defesa ${ }^{15}$ aparentemente menos custoso, mais econômico, porém, mais devastador àquele que se aplica.

São nas pequenas comunidades que os indivíduos se conhecem e mantém redes de relacionamento estreitas e próximas. O filme se passa em uma pequena cidade da Dinamarca, onde o personagem interpretado por Mads Mikkelsen trabalha como professor em um jardim de infância. Lucas tem uma boa relação com as crianças. É um professor extrovertido e tem uma proximidade afetuosa, quase paterna, por Klara, a filha de seu melhor amigo. Inicialmente já existe uma problemática de gênero na relação demonstrada pelo filme, pois o

\footnotetext{
${ }^{14}$ No começo de sua obra, Becker (2008) define o conceito de Outsider como aquele que quebra a regra social imposta pelo grupo dominante. O grupo dominante possui certos valores considerados como "normais", enquanto a ação do desviante é algo excessivo a esse padrão, cujo rótulo será aplicado com sucesso ao sujeito se ele se mantiver numa carreira moral do desvio.

${ }^{15}$ Trata-se de funções inconscientes do ego. O indivíduo se defende de algo, mas não tem absoluta consciência do que está se defendendo, sendo o mecanismo que mais se aproxima desta definição denominado projeção, onde o indivíduo transfere suas pulsões a outro.
} 
personagem é um professor homem e jovem, que assume um papel socialmente construído em torno da figura de um instrutor de crianças, nesse caso no cuidado delas na creche.

Os membros da comunidade em que Lucas estava inserido viram como um traço de anormalidade o comportamento de um sujeito que, somando todos os rótulos imputados homem, jovem, professor, divorciado -, fugiu do esperado pelas regras sociais, agredindo ferozmente não somente o Direito, como também uma moral que todos tinham como inerte e imutável. Quanto maior o estigma, maior a produção de controle social. E assim, quanto mais se foge ao padrão esperado pela comunidade, maior será a visibilidade estigmatizante do indivíduo (GOFFMAN, 2013).

Focando-nos agora na história de Klara, vemos a representação de uma menina solitária que possui transtorno obsessivo compulsivo (TOC) e uma relação familiar conturbada, frequentemente acontecendo brigas entre seus pais. Ela estuda com outras crianças numa pequena creche em que Lucas trabalha. $\mathrm{O}$ professor é muito atencioso com a menina, pois se encontra presente em muitos momentos que seus pais estão ausentes, momentos difíceis na vida da garota, quando, por exemplo, ela não consegue voltar para casa porque os pais a esqueceram na escola. A menina nutre uma paixão infantilizada ${ }^{16}$ pelo professor e, em certo dia, entrega um coração de brinquedo para Lucas que, no momento, brincava de vivo-morto com a garota. Quando Lucas fecha os olhos, a menina lhe dá um beijo na boca. O professor então imediatamente afirma para menina que ela não devia fazer aquilo e alerta que não pode aceitar o presente, sendo melhor que ela o entregasse aos pais.

A menina se sente contrariada com Lucas e, num dia em que o professor vai embora da escola, a diretora a aborda e pergunta se está tudo bem, pois Klara se encontra visivelmente triste frente à situação de contrariedade. A menina, conforme o informa que está com raiva de Lucas e o acha "feio e chato", argumenta ainda que Lucas possui um pênis. Em um primeiro momento, a diretora faz um comentário isento de julgamento, ou seja, diz que todos os meninos têm um pênis e que isso é normal, mas Klara alega que o de Lucas ficara para cima e "apontava para ela como uma vara". A diretora da creche então questiona a menina se, por ventura, ela havia visto o pênis do professor, e a menina, hesitante, diz que não, mas com insistência da diretora a menina move a cabeça de forma positiva.

\footnotetext{
${ }^{16} \mathrm{O}$ trabalho não pretende abordar questões psicanalíticas a respeito da relação entre Klara e Lucas. No entanto, cabe esclarecer que a infância não é um momento de pureza e não-sexualidade, mas sim que, segundo a concepção freudiana, se trata do desenvolvimento "de afetos, desejos e conflitos, que ainda hoje temos dificuldade em aceitar a sexualidade infantil proposta pelo fundador da psicanálise" (ABU-JAMRA ZORNIG, 2008, p. 2).
} 
$\mathrm{Na}$ rede-social dos personagens do filme, que se conhecem e mantém elos de amizade na caça, no convívio em jantares, etc., não há lugar que se possa escapar do prejulgamento, da desconfiança e da formação de preconceitos. A notícia se espalha sobre um suposto abusador na escola, a diretora chama um profissional para conversar com Klara, os pais são reunidos na escola para uma grande reunião. As pessoas ficam sabendo do fato e a rede de relações é estreita demais para ser quebrada. Não se trata de uma cidade grande ${ }^{17}$. O homem merece, portanto, punição, porque é um estranho, é um desviante, um hostis. Os conceitos de hostis e outsider se aproximam em relação às consequências do evento social. A figura do hostis, que significava "o estrangeiro, o inimigo, o hostis, era quem carecia de direitos em termos absolutos, quem estava fora da comunidade" (ZAFFARONI, 2007, p. 2122), e, portanto, era passível de ser fortemente punido, se atrela ao do outsider, completando uma privação tanto social quanto penal do sujeito. Podemos dizer que ele "cumprirá" dois tipos de pena.

\section{AS REAIS CONSEQUÊNCIAS DA ACUSAÇÃO E O ESTIGMA}

Na obra Outsiders, Becker traça os caminhos essenciais para mostrar o paradigma da reação social ligado a pessoas que estavam inseridas em comportamentos considerados desviantes, advindos de processos sociais de interação e relacionamento com os demais integrantes do grande grupo denominado sociedade. Logo, o rótulo é atribuído ao indivíduo e este pode vir a assumi-lo ou não dentro de uma carreira pertencente a determinado grupo, e conforme assim o fizer, tornará sua identidade desviante concreta. Sua obra dá um passo importante para concretização da criminologia crítica, uma vez que rompe com a ideia etiológica do crime, isto é, trabalhar com as causas da delinquência.

Quando a notícia se espalha entre os pais das crianças e por toda a pequena cidade, acontece a já citada "deterioração da identidade" prevista por Goffman. Em pouco tempo, dentro de um ou dois dias, toda a comunidade que circundava Lucas sabia da acusação. Antes, um professor respeitado, benquisto pelos amigos, que participava de todos os ritos que aconteciam na cidade, que começava a se recuperar do relacionamento anterior, agora, após a acusação, um desviante. As notícias se espalham dentro de uma pequena sociedade fortemente

\footnotetext{
17 "Quando o "sistema de referência" é deslocado de uma comunidade local de contatos face-a-face para o mundo mais amplo dos aglomerados metropolitanos (e suas áreas conexas, de recursos e residenciais), verificase um deslocamento correspondente na variedade e no significado dos desvios" (GOFFMAN, 2013, p. 120).
} 
ligada em redes estreitas de relacionamentos. Para Goffman, existem três tipos de estigma nitidamente diferentes entre si e que podem fazer parte da vida do indivíduo. Lucas se encaixa no segundo tipo:

Em primeiro lugar, há as abominações do corpo - as várias deformidades físicas. Em segundo, as culpas de caráter individual, percebidas como vontade fraca, paixões tirânicas ou não naturais, crenças falsas e rígidas, desonestidade, sendo essas inferidas a partir de relatos conhecidos de, por exemplo, distúrbio mental, prisão, vicio, alcoolismo, homossexualismo, desemprego, tentativas de suicídio e comportamento político radical (GOFFMAN, 2013, p. 7).

A notícia particular deste caso, mesmo sem nenhum tipo de averiguação de provas sérias se espalha pela cidade. As consequências são imediatas: o isolamento da escola, a casa depredada, o cachorro morto, as agressões ao filho, o fim de um relacionamento amoroso. Lucas tem a vida completamente transfigurada. "Quando conhecida ou manifesta, essa discrepância estraga a sua identidade social; ela tem como efeito afastar o indivíduo da sociedade e de si mesmo de tal modo que ele acaba por ser uma pessoa desacreditada frente a um mundo não receptivo" (GOFFMAN, 2013, p. 20). O isolamento é tal que Lucas tem negada a entrada em um mercado dentro da cidade, e ignorando o aviso, é fortemente agredido levando socos e pontapés do açougueiro. Ninguém faz nada, a violência acontece aos olhos nus. Algo semelhante acontece com seu filho, após ter cuspido na menina Klara por acreditar que ela estava mentindo.

O pânico moral se estabeleceu na pequena cidade. Não se trata de ser um pânico alucinado, ele é um pânico real. As crianças da creche começam a relatar outros abusos, inclusive dentro de um porão que Lucas possuía em sua casa. A realidade socialmente construída de até então é deformada pelo pânico e pelo medo, oferecendo as justificativas necessárias para cessarem o mal o mais rápido possível. O estigma sofrido por Lucas é tão forte que as minúcias de sua vida privada são alvo de intensas especulações, sua aparência de um homem jovem que cuida de crianças é problematizada a exaustão e, portanto, fácil de ser estigmatizada: "A existência de um objeto portador de algo de desconhecido ou dano facilita a tarefa de manipulá-lo até fazer crer que é necessário aniquilá-lo para sobreviver" (ZAFFARONI, 2013, p. 242). Não há investigação, tampouco um conjunto de provas contundentes que façam presumir ser ele o autor do estupro, o que se sobressalta na notícia é o medo e o pânico dos moradores da comunidade.

O teorema de William Thomas, um dos pioneiros da Escola de Chicago, ao qual Goffman e Becker são filiados, se aproxima da definição do que acontece no filme: "Se os homens definem situações como reais, elas são reais em suas consequências" (THOMAS, 
1928, p. 512). A "profecia autorrealizável"18 se apresenta no filme, mesmo não ocorrendo de fato a violação de uma regra (estupro), mas sim uma falsa violação. A acusação de estupro de uma garotinha de cinco anos de idade é algo por demais sério do ponto de vista moral da sociedade. É utilizando-se da violência com as próprias mãos que a população encontra a sua defesa contra este "mal" presente.

\begin{abstract}
A sociedade estabelece um modelo de categorias e tenta catalogar as pessoas conforme os atributos considerados comuns e naturais pelos membros dessa categoria. Estabelece também as categorias a que as pessoas devem pertencer, bem como os seus atributos, o que significa que a sociedade determina um padrão externo ao indivíduo que permite prever a categoria e os atributos, a identidade social e as relações com o meio. Criamos um modelo social do indivíduo e, no processo das nossas vivências, nem sempre é imperceptível a imagem social do indivíduo que criamos; essa imagem pode não corresponder à realidade, mas ao que Goffman denomina de uma identidade social virtual. Os atributos, nomeados como identidade social real, são, de fato, o que pode demonstrar a que categorias o indivíduo pertence (DE MELO; DEUSTO, 2000, p. 1).
\end{abstract}

Jock Young (2002) tem uma posição clara acerca do inimigo que ronda as comunidades e dos elementos necessário para criação de um "bom inimigo". Para o autor (i) deve existir os necessários elementos que convençam as pessoas de que ele é a causa de todos os males que acontecem em sociedade e ainda que (ii) eles, os inimigos, constituem essencialmente pessoas que são diferentes, que não seguem os hábitos da cidade, portanto, assim, não pertencem a ela, por possuírem vícios, trazerem corrupção e maldade ao ethos que os cerca. Existe uma conjuntura criminológica que se denomina de "cultura da punição", sendo esta integrante de um sistema punitivo explanado por Zaffaroni no tratamento de inimigo ou hostis dado a alguns indivíduos, e por onde a resolução dos conflitos sociais perpassa um processo de exclusão e punição, violando-se direitos e garantias fundamentais e desencadeando consequências como os linchamentos presentes durante o filme.

Ao final, apesar de sua inocência ser provada pelas autoridades, o estigma social como marca de deterioração é carregado pelo protagonista, o que o incapacita para a inclusão social. Num processo em que não são oferecidas outras formas de resolução dos problemas sociais, a punição só dá consenso e legitimação a uma cultura punitiva, onde a vitimização só aumenta o mal produzido.

\footnotetext{
${ }^{18}$ Uma profecia autorrealizável é uma crença que, por ser entoada por um grande número de pessoas que possuem relações entre si, acaba se tornando verdadeira, mesmo não o sendo. Um dos exemplos mais conhecidos de profecias autorrealizáveis é o da corrida aos bancos de Robert Merton (1995), onde o boato de que um banco está em dificuldades faz com que seus clientes tirem o dinheiro do banco e acabem por fali-lo de fato.
} 
E mesmo não existindo provas do seu crime, Lucas continua sendo suspeito. Inocentado na justiça, após se reunir com os amigos para um almoço no aniversário do filho, a tensão no olhar ainda se reproduz. Mesmo quando em uma cena, fica a sós com a garotinha Klara, seu corpo está paralisando, seu inconsciente mantém a distância que nunca mais irá se reatar. O personagem continua condenado, e dificilmente vai alcançar seu reconhecimento enquanto sujeito de confiança. A responsabilização que se recai, não se reata, o sacrifício do caçador já foi feito no momento em que a acusação se espalha pela cidade.

\section{CONSIDERAÇÕES FINAIS - A RESOLUÇÃO DE CONFLITOS DENTRO DE PEQUENAS COMUNIDADES}

O poder punitivo está crescendo em instituições públicas, no seio de comunidades, nos centros urbanos e dentro de lares. Quando os habitantes de determinado lugar não reconhecem humanidade em seus integrantes que fazem parte dos mesmos elos, das mesmas reações, quando não adotam práticas de resolução de conflitos que perpassam direitos humanos e que sejam de natureza pacífica, o poder punitivo vence. Continua-se mantendo e aplaudindo o espetáculo da violência. $\mathrm{O}$ futuro se torna obscuro. Vidas são fragmentadas e destruídas. Problemas na esfera privada possuem soluções interpessoais em contextos privados, que devem ser mediados entre as pessoas que estão próximas. Hulsman (1993) e Christie $(2011$; 1998) são exemplos de pesquisadores da criminologia que apresentam estudos onde mostram que a punição não soluciona conflitos.

Como colocam os autores Hulsman \& Celis, ao se referir ao sistema penal, aboli-lo, isto é, abolir o modo punitivo de resolução de conflito significa "Dar vida às comunidades, às instituições e aos homens" (HULSMAN; CELIS, 1993, p. 92). Para o autor é muito comum que as pessoas envolvidas no crime busquem, inicialmente, as pessoas mais próximas para resolver o conflito. São instrumentos comuns de resolução. Aconselharem-se com pessoas próximas e alcançarem uma solução. O conceito de community boards demonstra que a pacificação através de mediadores dentro da comunidade torna-se de maior eficácia para não se agregar mais punição e sofrimento às pessoas.

Estes conciliadores formam comissões ad hoc, compostas de membros escolhidos de acordo com as pessoas que solicitam a intervenção do Community Board. Se o conflito se dá entre portorriquenhos ou entre mexicanos, há pelo menos um portorriquenho ou um mexicano na comissão; se o conflito opõe um homem a uma mulher, terá que haver ali um homem e uma mulher; se o conflito se desenvolveu 
entre um comerciante e jovens, terão que estar ali um comerciante e jovens. A ideia básica é a de que os membros da comissão sejam pessoas próximas dos implicados no conflito. Outra ideia igualmente importante caracteriza este modelo de resolução de conflitos: os conciliadores não são preparados para resolver conflitos, mas sim treinados para não propor soluções. Eles são formados para ajudar as pessoas a reconhecerem por si mesmas a natureza do conflito, a escutarem umas às outras, a procurarem compreender a situação vivida pelo outro e, afinal, a decidirem o que fazer com o conflito: retomá-lo e em que contexto, ou encerrá-lo ali. (HULSMAN; CELIS, 1993, p. 134).

Os conflitos são transformados em situações problemáticas e que podem ter soluções positivas se as partes participam e tentam buscar um denominador comum entre ambas. $\mathrm{O}$ encontro face-a-face entre os conflitantes é "“[...] similar a modelos de solução de conflitos (compensatório, terapêutico, educativo, assistencial, etc.) que, diferentes do modelo punitivo, têm a vantagem e não serem, ao contrário deste modelo - cuja aplicação exclui, automaticamente, os restantes - necessariamente alternativos". (ZAFFARONI, 1991, p. 99). Como no exemplo de Christie (1998), quando um familiar, isto é, uma pessoa muito próxima das nossas relações comete uma conduta reprovável, que inclusive possa ser crime na legislação, em geral, as pessoas não buscam o sistema penal, a exclusão e a deterioração. $\mathrm{Na}$ maioria das vezes, quando o conflito é familiar ou entre amigos, a mediação e o diálogo são as principais formas pacíficas e humanizadoras de resolução do conflito em questão. Portanto, a busca de alternativas e de perspectivas que não sejam violentas deve estar no horizonte do alcançável.

Por fim, Goffman e Zaffaroni colocam que admitir um tratamento diferenciado, seja ao estigmatizado, seja ao inimigo, se configura em "exercer um controle social mais autoritário sobre toda a população, como único modo de identifica-los e, ademais, impor a toda a população uma série de limitações à sua liberdade" (ZAFFARONI, 2007, p. 118). Aumentar o controle social da sociedade dá margem ao aumento do controle punitivo, e isso contribui para que a punição seja elencada como a resolução mais apropriada dos conflitos sociais. Vamos à cena notável do filme: Lucas entra na Igreja, chorando, cantando alto, com raiva e com dor, totalmente embriagado, e então é retirado, expulso da igreja, expulso da sociedade, condenado. A profecia se realiza:

Tratar uma pessoa como se ela fosse em geral, e não em particular, desviante produz uma profecia auto-realizadora. Ela põe em movimento vários mecanismos que conspiram para moldar a pessoa segundo a imagem que os outros têm dela. Em primeiro lugar, após ser identificada como desviante, ela tende a ser impedida de participar de grupos mais convencionais, num isolamento que talvez as consequências específicas da atividade desviante nunca pudessem causar por si mesmas caso não houvesse o conhecimento público e a reação a ele (BECKER, 2008, p. 44) 
Quando o estigma de estuprador é aplicado a Lucas, todas as suas outras atribuições morais desaparecem. Toda sua trajetória de vida, suas ações boas, suas qualidades, seus papeis vividos em sociedade, como professor, como pai, como amigo, tudo o que ele fez de positivo para as pessoas que o cercam é destruído. O estigma tende a canalizar o mal e a rotulação negativa é feita de forma que tudo se resuma a ser o estuprador.

Uma das formas de resolução para tratar o conflito, do ponto de vista abolicionista, é a responsabilização da comunidade que cerca o indivíduo. Estreitar os laços pacíficos e buscar uma resolução que torne o indivíduo mais humano e a sociedade mais responsável. A exclusão do inimigo, do hostis, do estigmatizado ou do outsider só produz uma maior violência. As chances de dor e sofrimento são potencializadas. O caçador de uma pequena comunidade vira caça de uma população que quer sua punição. Abolir vínculos estigmatizantes significa valorar novos costumes, criar uma comunidade mais pacífica que pode se auto gerir em desenvolver soluções de conflitos com sua própria população, práticas libertárias, de indivíduos que se conhecem e mantém relações uns com os outros. Dispensar a forma punitiva tanto do Estado quanto aquela que ronda as relações entre as pessoas é o que se busca.

\section{REFERÊNCIAS}

ABU-JAMRA ZORNIG, Silvia Maria. As Teorias Sexuais Infantis na Atualidade: Algumas Reflexões. Psicologia em estudo, v. 13, n. 1, 2008.

A Caça. [filme-vídeo] M. Kaufmann, S. Jørgensen. prod., T. Vinterberg, dir. Dinamarca: 2012. Nordisk Film. 106 min.

ANDRADE, Vera Regina Pereira de. Do Paradigma Etiológico Ao Paradigma da Reação Social: mudança e Permanência de Paradigmas Criminológicos na Ciência e no Senso Comum. Revista Seqüência, Florianópolis, n. 30, 1995.

BECKER, Howard. Outsiders: Estudos de Sociologia do Desvio. Tradução de Maria Luiza X. Borges. Rio de Janeiro: Zahar, 2008. 
CHRISTIE, Nils. Uma Razoável Quantidade de Crime. Tradução de André Nascimento, Rio de Janeiro: Revan, 2011.

A Indústria do Controle do Crime. Tradução Luis Leiria. Rio de Janeiro:

Forense, 1998.

DE MELO, Zélia Maria; DEUSTO. Os Estigmas: a Deterioração da Identidade Social. 2000. Disponível em:

$<$ http://efpava.cursos.educacao.sp.gov.br/Resource/282783,563,5E1/Assets/NB/pdf/nb_m07t0 3.pdf> Acesso em: 12 de mar. 2017.

DURKHEIM, Émile. Da Divisão do Trabalho Social. São Paulo: Editora Abril. 1983.

FOCUCAULT, Michel. Vigiar e Punir. Rio de Janeiro, Editora Vozes, 2011.

GOFFMAN, Erving. Estigma: notas sobre a manipulação da identidade deteriorada. $3^{\mathrm{a}}$ ed. Editora LTC, 2013.

HULSMAN, Louk; CELIS, Jacquelinie Bernat de. Penas Perdidas: o sistema penal em questão. Niterói: Luam, 1993

MERTON, Robert K. The Thomas Theorem and the Matthew effect. Social forces, v. 74, n. 2, p. 379-422, 1995.

THOMAS, William Isaac; THOMAS, Dorothy Swaine. The Child in America: Behavior Problems and Programs. Nova York, Knopf, 1928.

YOUNG, Jock. A Sociedade Excludente: Exclusão Social, Criminalidade e Diferença na Modernidade Tardia. Rio de Janeiro: Revan, 2002.

ZAFFARONI, Eugenio Raul. A Questão Criminal. Tradução Sergio Lamarão. Rio de Janeiro: Revan, 2013. 
. Em Busca das Penas Perdidas. Rio de Janeiro: Revan, 1991.

. O inimigo no Direito Penal. Tradução de Sergio Lamarão. Rio de Janeiro: Revan, 2007.

\title{
THE IMPACTS OF THE FALSE ACCUSATION IN SMALL COMMUNITIES: POSSIBLE MEETINGS BETWEEN SOCIOLOGY AND CRIMONOLOGY IN THE FILM "THE HUNT"
}

\begin{abstract}
This paper aims to demonstrate some perspectives of sociology and criminology before a false accusation of rape within a small community, if this one contained in the film "The hunt". Using a theoretical basis of the two disciplines, the present effort seeks to disentangle the punitive demand present in the artificial community of the film before the hypothetical commitment of a sexual crime. The plot unfolding shows us a population that does not recognize (and reproduce) its basic rights, as a presumption of innocence, ample defense and contradictory. Our analysis will be developed from an investigation of the cinematographic work in question, joining the use of concepts from both disciplines to justify our interpretations of the events. This work aims to demonstrate some perspectives of sociology and criminology before a false accusation of rape within a small Community, if this is contained in the movie "The Hunt". Using a theoretical basis of the two disciplines, the present effort seeks to disentangle the punitive demand present in the artificial community of the film before the hypothetical commitment of a sexual crime. The plot unfolding shows us a population that does not recognize (and reproduce) its basic rights, as a presumption of innocence, ample defense and contradictory. Our analysis will be developed from an investigation of the cinematographic work in question, uniting to the use of concepts of both disciplines to justify our interpretations of the events.
\end{abstract}

Keywords: Criminology. Sociology. Thomas's theorem. Labeling. Stigmatization. 